\title{
Energy-dispersive X-ray Microanalysis of Membrane-associated Inclusions in Hydrogenosomes Isolated from Trichomonas vaginalis
}

\author{
By ALAN CHAPMAN, ${ }^{*}$ AO C. HANN, ${ }^{1}$ DAVID LINSTEAD ${ }^{2}$ AND \\ DA VID LLOYD ${ }^{1}$ \\ ${ }^{1}$ Department of Microbiology and the College Electron Microscope Unit, University College, \\ Newport Road, Cardiff CF2 ITA, UK \\ ${ }^{2}$ Department of Biochemical Parasitology, Wellcome Research Laboratories, Langley Court, \\ Beckenham, Kent BR3 3BS, UK
}

(Received 11 March 1985; revised 3 July 1985)

Energy-dispersive X-ray microprobe analysis of electron-dense inclusions in hydrogenosomes isolated from the aerotolerant anaerobic protozoal human parasite Trichomonas vaginalis, Bushby strain, indicated the presence of high levels of $\mathrm{Mg}, \mathrm{P}$ and $\mathrm{Ca}$. This suggested that divalent cation (e.g. $\mathrm{Ca}^{2+}$ or $\mathrm{Mg}^{2+}$ ) accumulation by hydrogenosomes may be important in the regulation of intracellular ion concentrations.

\section{INTRODUCTION}

Trichomonads are aerotolerant anaerobic protozoa (Honigberg, 1978 $a, b$; Müller, 1980) characterized by the absence of mitochondria and the presence of hydrogenosomes (Lindmark $\&$ Müller, 1973). Although the pathways of carbon flow involved in pyruvate oxidation by these organelles are well established (Čerkasov et al., 1978; Müller \& Lindmark, 1978) and some information on electron transport components is available (Lloyd et al., 1979; Ohnishi et al., 1980; Marczak et al., 1983), a clear physiological function has still to be established. This is emphasized by the recent observations that a mutant of the cattle parasite Tritrichomonas foetus that lacks a fully-functional hydrogenosome grows well in culture (Čerkasovová et al., 1984).

A study of sites of calcium accumulation in Tritrichomonas foetus (Benchimol et al., 1982) led to the suggestion that the hydrogenosome may be involved in the control of intracellular $\mathrm{Ca}^{2+}$ levels. Osmiophilic granules associated with the chromatic granules in Trichomonas vaginalis were first reported by Nielsen (1976). In the present paper we investigate the nature of intrahydrogenosomal inclusions in these organelles by energy-dispersive $\mathrm{X}$-ray microanalysis.

\section{METHODS}

Growth of the organisms and isolation of hydrogenosomes. This was as described in Chapman et al. (1985).

Electron microscopy and microprobe analysis. The samples were centrifuged at 1500 r.p.m. for $5 \mathrm{~min}$ in an MSE Centaur centrifuge and the resulting pellet was divided into small cubes $\left(1 \mathrm{~mm}^{3}\right)$ which were fixed at $4{ }^{\circ} \mathrm{C}$ for $1 \mathrm{~h}$ in $3 \%(\mathrm{v} / \mathrm{v})$ glutaraldehyde in $0 \cdot 1 \mathrm{M}$-sodium cacodylate buffer, $\mathrm{pH} \mathrm{7.4.} \mathrm{After} \mathrm{fixation,} \mathrm{the} \mathrm{specimens} \mathrm{were} \mathrm{rinsed} \mathrm{at}$ $4{ }^{\circ} \mathrm{C}$ for $20 \mathrm{~min}$ in $0 \cdot 1 \mathrm{M}$-cacodylate buffer $(\mathrm{pH} \mathrm{7.4)}$ ), dehydrated in a graded series of acetone and embedded in Epon. After polymerization, the resin block was cut on a Reichert OMU4 microtome. Thick sections $(0 \cdot 1-0 \cdot 2 \mu \mathrm{m})$ were collected on carbon-coated aluminium grids (200 mesh) and observed in a Philips EM $400 \mathrm{~T}$ electron microscope equipped with an EDAX 9100/60 analyser. The grids containing unstained sections were placed in a beryllium low-background holder tilted $25^{\circ}$ to the detector. Micro-analysis was done using a beam of $0 \cdot 1-0 \cdot 2 \mu \mathrm{m}$ diameter, an accelerating voltage of $80 \mathrm{kV}$, a beam current of $30 \mu \mathrm{A}$, and a magnification of $1700 \times$. The spectra were collected in $100 \mathrm{~s}$ live time, with typical X-ray counts around 1000-2000 c.p.s. Regions containing electronopaque granules, adjacent agranular zones and resin areas were analysed. After micro-analysis, these sections were post-stained with $3 \%(w / v)$ aqueous uranyl acetate and $1 \%(w / v)$ lead citrate and electron micrographs of analysed areas were taken. 
Freeze-substitution and $X$-ray mapping. Hydrogenosomes were sedimented at 2000 r.p.m. for 5 min in an MSE Centaur centrifuge, quenched in liquid $\mathrm{N}_{2}$ slush using a Harland liquid nitrogen slusher and quickly transferred to a vessel containing pre-cooled diethyl ether $\left(-70^{\circ} \mathrm{C}\right)$ and silica gel. The specimens were maintained at $-70^{\circ} \mathrm{C}$ for $72 \mathrm{~h}$, after which the temperature of the freezer (LEC) was increased to $-40^{\circ} \mathrm{C}$ for $48 \mathrm{~h}$. Lowicryl HM (Calemalm et al., 1981) was then allowed to infiltrate the pellet at $-40^{\circ} \mathrm{C}$ for $18 \mathrm{~h}$. Resin polymerization was done under UV light at $-40^{\circ} \mathrm{C}$ for $24 \mathrm{~h}$ and was followed by further hardening at room temperature for $48 \mathrm{~h}$ to improve the sectioning quality. Sections were cut and mounted as described above.

$\mathrm{X}$-ray mapping was done using the EDAX system (described above) in conjunction with a scanning transmission electron microscope unit (STEM). Microanalyses were done using a $0 \cdot 2 \mu \mathrm{m}$ beam diam and $150 \mu \mathrm{m}$ aperture. The field was scanned twice (scanning time about $5 \mathrm{~min}$ ) and electron micrographs were recorded on Kodak Tri-X pan film. Microdot analyses were done by focusing on inclusions, using a spot size of $0 \cdot 2 \mu \mathrm{m}$.

\section{RESULTS AND DISCUSSION}

Fig. 1 shows ultra-thin sections of a hydrogenosomal-enriched fraction prepared from $T$. vaginalis after staining with uranyl acetate and lead citrate. The organelles appeared as oblate spheroids, about $0.7 \times 0.5 \mu \mathrm{m}$ in size. The intrahydrogenosomal inclusions were evident as electron-dense bodies located at one end of the ellipsoidal organelle profiles just within the membrane limiting the organelle. In some cases, granules appeared to be separated from the main volume of the interior by an underlying membrane (Fig. 1b). Although not observed in every organelle (perhaps as a consequence of the plane of sectioning), the granules (about $0.13 \times$ $0.06 \mu \mathrm{m}$ in size) appeared in the majority (about $58 \%$ ) of sectioned organelles. Occasionally more than one granule per organelle was observed (Fig. $1 a$ ).

Energy-dispersive microprobe analyses of unstained glutaraldehyde-fixed samples on areas of $0 \cdot 1-0 \cdot 2 \mu \mathrm{m}$ diameter (Fig. $2 a$ ) indicated the presence of the following elements in the granules $\left(\mathrm{K}_{\alpha}\right.$ lines; $\mathrm{keV}$ values in parentheses): $\mathrm{Na}(1 \cdot 040), \mathrm{Mg}(1 \cdot 252), \mathrm{Si}(1 \cdot 739), \mathrm{S}(2 \cdot 307), \mathrm{Cl}(2 \cdot 623), \mathrm{K}$ (3.316), $\mathrm{Ca}(3.693), \mathrm{Fe}(6.402)$ and $\mathrm{Cu}(8.044), \mathrm{Na}$ and $\mathrm{Mg}$ peaks were not well defined; background subtraction revealed low levels of these elements. It is only in this part of the spectrum that the background interfered with the readings; therefore, it was not routinely used in value correction. The large peak of $\mathrm{Al}(1.48 \mathrm{keV})$ arises from the $\mathrm{Al}$ grid. Semi-quantitative data, obtained by the ratio method, on typical inclusions from whole cells and isolated hydrogenosomes, are presented in Table 1 . All the window widths from 0-10 keV were used. Control experiments were done to analyse the hydrogenosome membrane (Fig. $2 b$ ), and the Epon resin of the thick section used (Fig. $2 c$ ). Apart from Al, the only elements observed in the resin were $\mathrm{Fe}$ and $\mathrm{Cu}$, which accounts for the signals in the spectrum of Fig. $2 a$.

$\mathrm{X}$-ray mapping (Fig. 3) revealed that there was a high concentration of $\mathrm{Ca}$ and $\mathrm{P}(b$ and $c$ ) localized in the region of the five hydrogenosome inclusions marked in the field shown in Fig. $3(a)$. Similar dot mapping of $\mathrm{Cl}(d), \mathrm{Fe}(e), \mathrm{Si}(f)$ and $\mathrm{Cu}(g)$ did not reveal a discretely localized elemental concentration, suggesting these elements are dispersed throughout the field. Dot mapping of $\mathrm{Mg}$ (not shown) also showed random scattering throughout the field of view although the results presented in Table 1 show similar levels to $\mathrm{Ca}$.

Fig. $4 a$ shows microanalysis of the entire field shown in Fig. 3(a), and Fig. $4(b)$ shows the microdot analysis of one of the inclusions (labelled X on Fig. $3 a$ ). Comparison of these two analyses clearly indicates the specific preponderance of $\mathrm{Ca}$ and $\mathrm{P}$ within the inclusion. Microdot analysis of inclusions of hydrogenosomes prepared by the freeze substitution method revealed similar proportions of elements compared to material prepared for the direct emission spectra.

The elevated levels of $\mathrm{Ca}$ and $\mathrm{P}$ in these granules suggested that they may be analogous to the inclusions containing calcium hydroxyapatite, $\left[\mathrm{Ca}_{3}\left(\mathrm{PO}_{4}\right)_{2}\right]_{3} \mathrm{Ca}(\mathrm{OH})_{2}$, observed in some mitochondria (Greenawalt et al., 1964), or possibly similar to the calcium magnesium pyrophosphate granules found in Tetrahymena pyriformis (Munk \& Rosenberg, 1969). Mitochondria play a key role in the regulation of cytosolic $\mathrm{Ca}^{2+}$ concentrations, and like the endoplasmic reticulum and plasma membrane, serve as special sites for the localization of $\mathrm{Ca}^{2+}$ pumping systems (Carafoli \& Crompton, 1978). Our observations support the suggestion of Benchimol et al. (1982) that calcium uptake may be as important a hydrogenosomal function in anaerobic protozoa as it is in the mitochondria of aerobes. Physiological and biochemical 


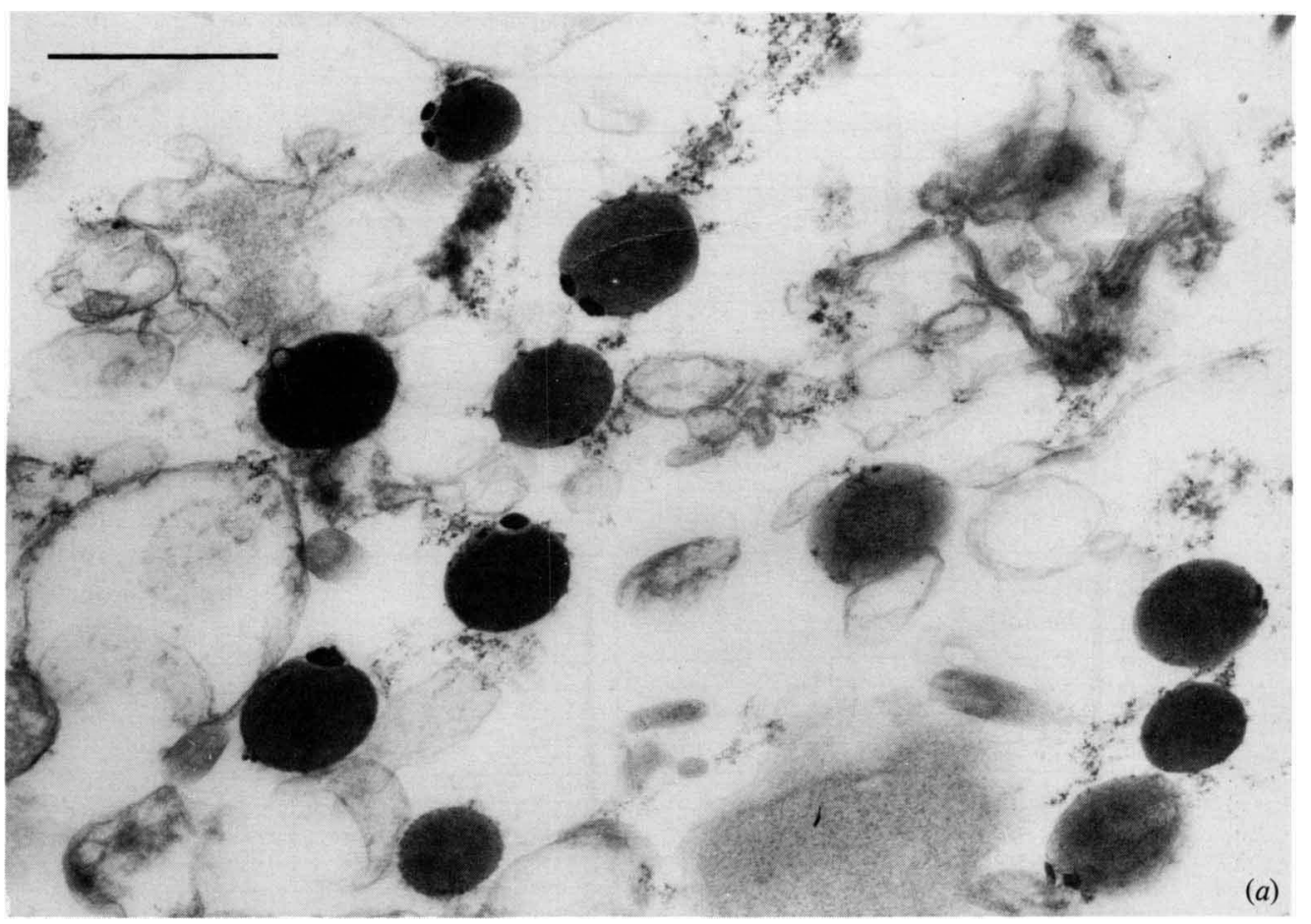

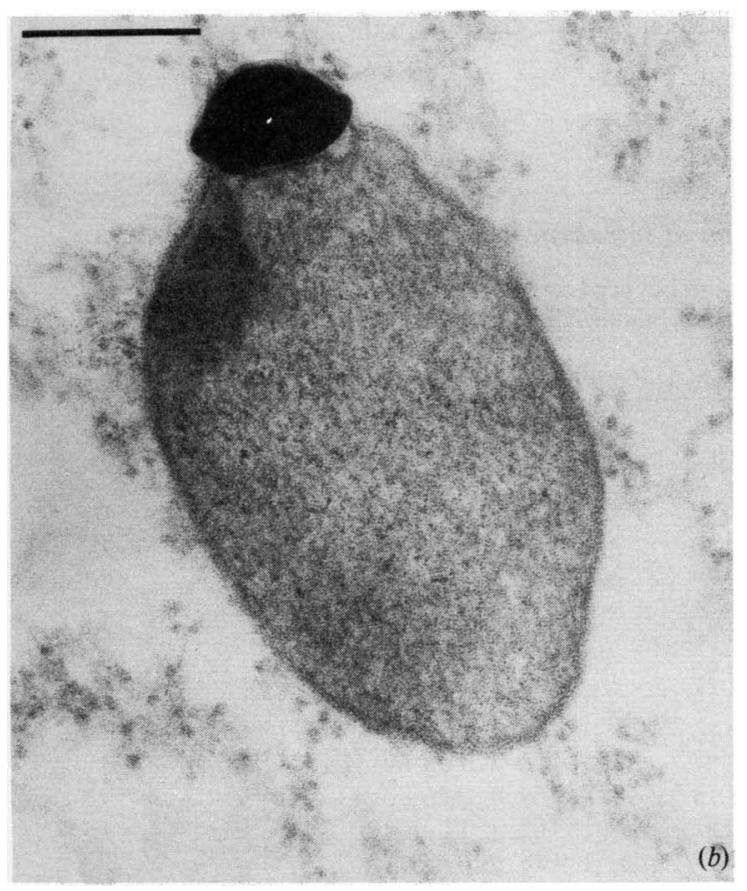

Fig. 1. Electron micrographs of thin sections of a hydrogenosome-enriched fraction from $T$. vaginalis. (a) Field showing several hydrogenosomes with electron-dense granules (bar represents $1 \mu \mathrm{m})$; (b) sectioned hydrogenosome showing a polar granule with underlying membrane (bar represents $0 \cdot 2 \mu \mathrm{m}$ ). 


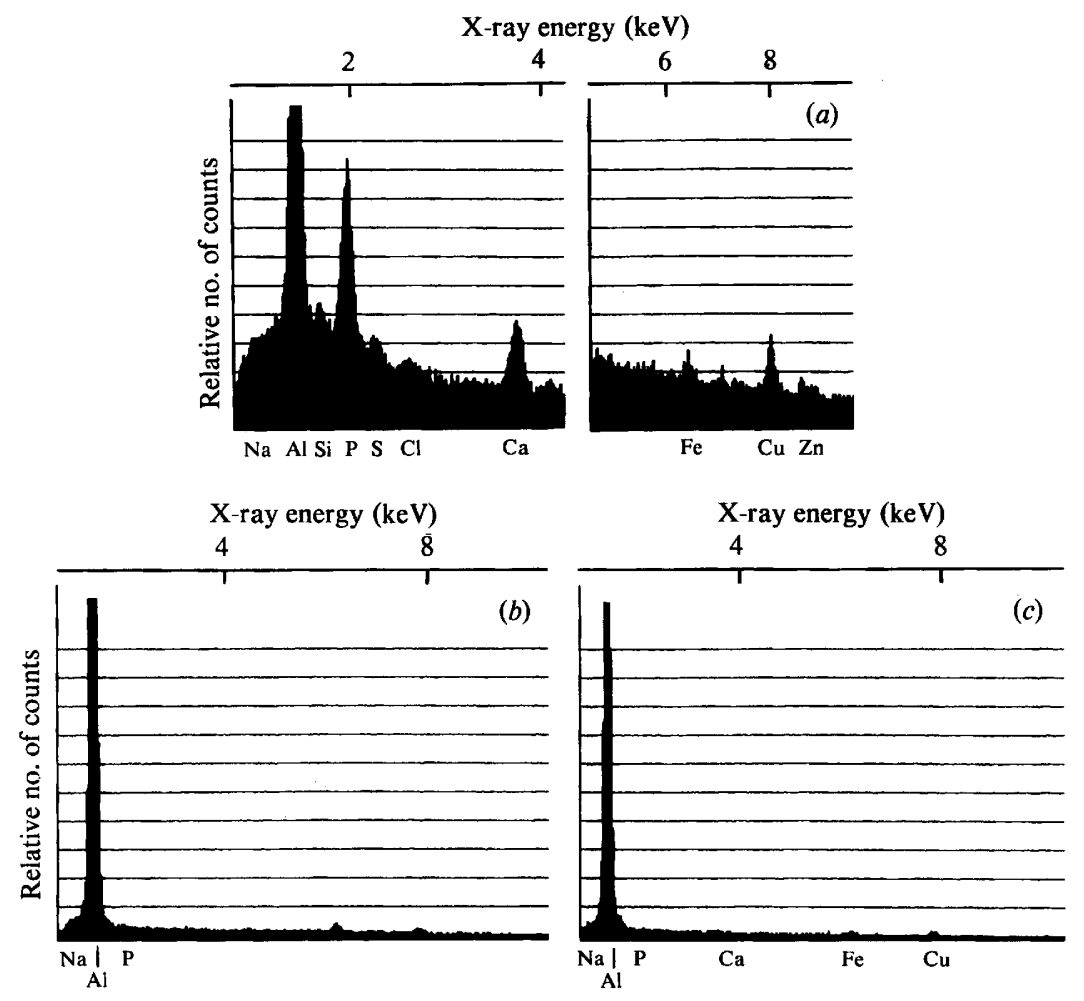

Fig. 2. X-ray microprobe analyses of $(a)$ intrahydrogenosomal granule, (b) hydrogenosome membrane and $(c)$ Epon resin background. The signal due to aluminium arises from the aluminium supporting grid.

\section{Table 1. Elemental composition of intrahydrogenosomal inclusions}

Relative proportions (expressed as wt $\% \pm 99 \%$ confidence limit) of some elements measured by X-ray microanalysis of intrahydrogenosomal inclusions of (glutaraldehyde fixed, acetone dehydrated) whole cells and isolated hydrogenosomes.

\begin{tabular}{crc} 
& \multicolumn{2}{c}{ Proportion in granule } \\
\cline { 2 - 3 } Element & $\begin{array}{c}\text { Whole cells } \\
(24 \text { samples })\end{array}$ & $\begin{array}{c}\text { Isolated hydrogenosomes } \\
(27 \text { samples })\end{array}$ \\
$\mathrm{Na}$ & $6.73 \pm 1.40$ & $6.21 \pm 1.00$ \\
$\mathrm{Mg}$ & $15.03 \pm 0.79$ & $14.53 \pm 1.78$ \\
$\mathrm{Si}$ & $11.61 \pm 3.45$ & $3.50 \pm 0.47$ \\
$\mathrm{P}$ & $46.53 \pm 3.06$ & $48.75 \pm 4.86$ \\
$\mathrm{~S}$ & $1.66 \pm 0.90$ & $0.77 \pm 0.36$ \\
$\mathrm{Cl}$ & $0.82 \pm 0.53$ & $3.69 \pm 1.28$ \\
$\mathrm{~K}$ & $1.59 \pm 0.26$ & $2.18 \pm 0.27$ \\
$\mathrm{Ca}$ & $8.66 \pm 1.01$ & $9.89 \pm 1.25$ \\
$\mathrm{Fe}$ & $4.82 \pm 1.15$ & $3.08 \pm 0.56$ \\
$\mathrm{Cu}$ & $1.97 \pm 0.81$ & $3.68 \pm 1.00$ \\
$\mathrm{Zn}$ & $0.22 \pm 0.18$ & $0.58 \pm 0.18$
\end{tabular}



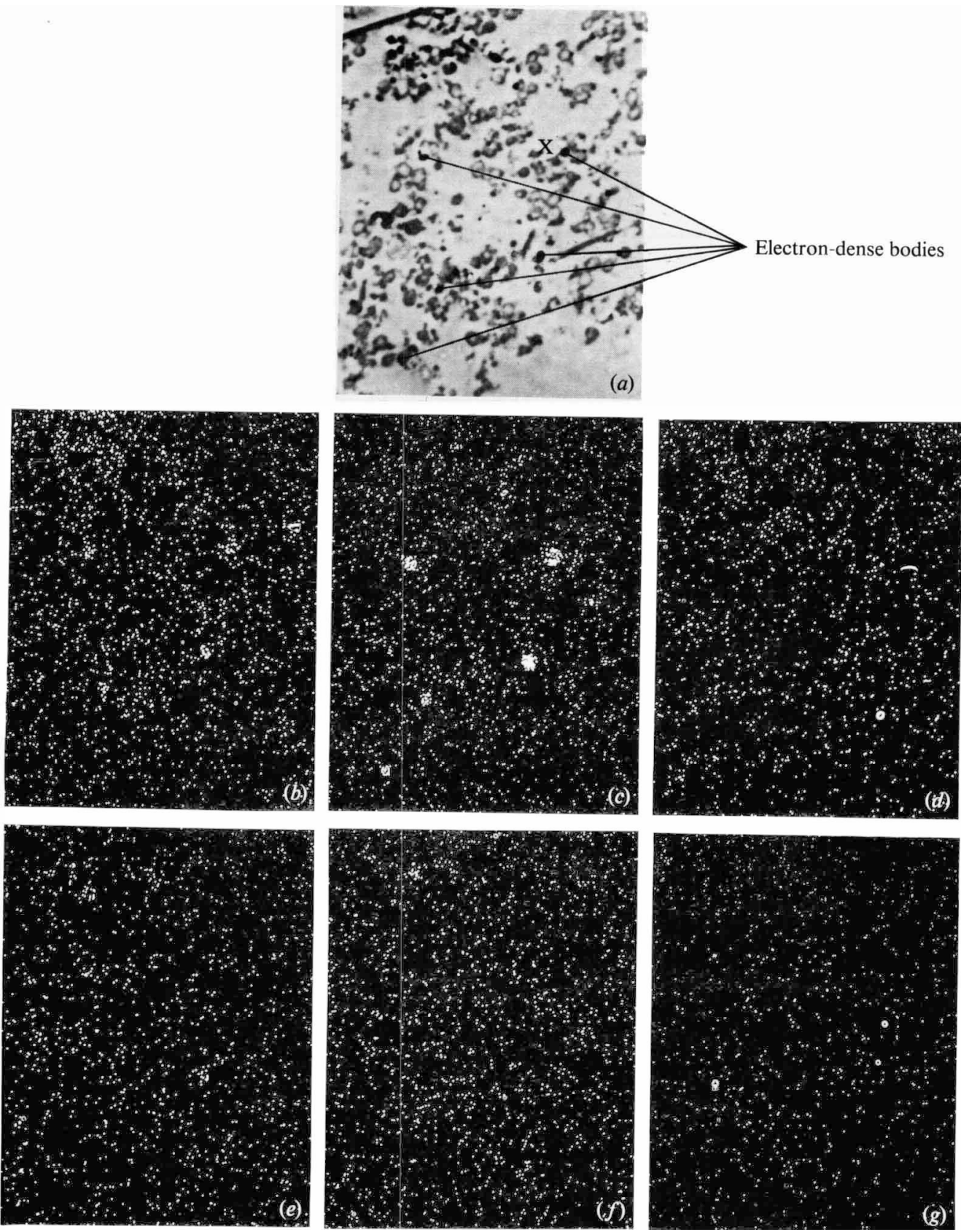

Fig. 3. X-ray mapping of a field of hydrogenosome-enriched fraction. (a) Electron micrograph of unstained section with five electron-dense inclusions; $(b-g) \mathrm{X}$-ray mapping of this field for $\mathrm{Ca}, \mathrm{P}, \mathrm{Cl}$, $\mathrm{Fe}, \mathrm{Si}$ and $\mathrm{Cu}$ respectively ( $5 \mathrm{~min}$ integration time). 

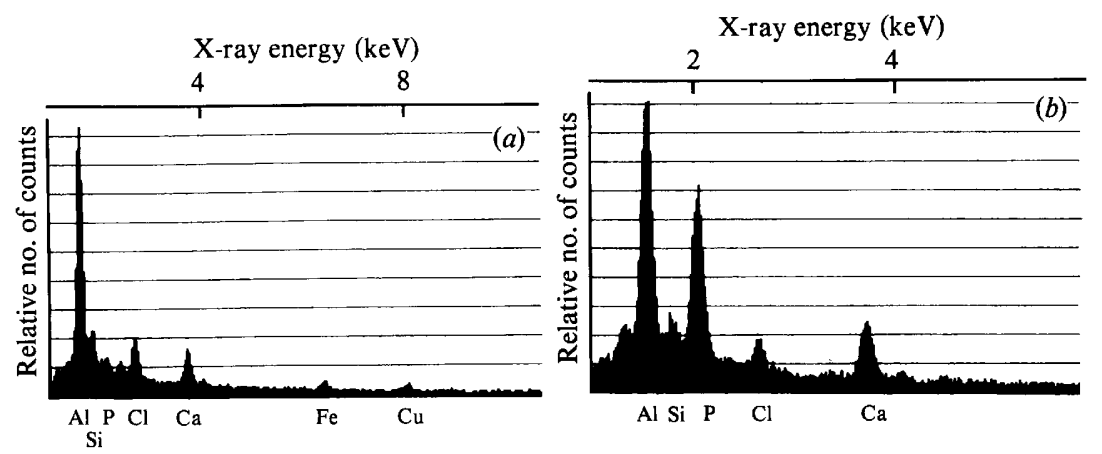

Fig. 4. X-ray microprobe analyses of (a) whole field of Fig. 3(a) and microdot analysis $(b)$ of inclusion X of Fig. $3(a)$.

confirmation of this suggestion awaits measurement of in vivo $\mathrm{Ca}^{2+}$ accumulation and characterization of a putative $\mathrm{Ca}^{2+}$ transport protein in the membrane of hydrogenosomes.

Where these techniques have been applied to other organelles (e.g., mitochondria; Appleton, 1978) high localized concentrations of $\mathrm{Na}, \mathrm{Mg}, \mathrm{Si}, \mathrm{Cl}$ and $\mathrm{K}$ have been observed also.

Other metals expected to occur in hydrogenosomes include the $\mathrm{Fe}$ and $\mathrm{S}$ of iron-sulphur proteins (Ohnishi et al., 1980), and an iron-containing superoxide dismutase (Lindmark \& Muller, 1974; Kitchener et al., 1984). Some of these are specifically located in membrane fractions obtained from isolated organelles (A. Chapman \& R. Cammack, unpublished observations).

Alan Chapman holds a SERC-CASE postgraduate studentship.

\section{REFERENCES}

APpleton, T. C. (1978). The contribution of cryoultramicrotomy to X-ray microanalysis in biology. In Electron Probe Microanalysis in Biology, pp. 148-182. Edited by D. A. Erasmus. London: Chapman \& Hall.

Benchimol, M., Elias, C. A. \& Desouza, W. (1982). Tritrichomonas foetus: ultrastructural localisation of calcium in the plasma membrane and in the hydrogenosome. Experimental Parasitology 54, 277284.

Calemalm, E., Garavito, R. M. \& Villiger, W. (1981). Resin development for electron microscopy and analysis of embedding at low temperature. Journal of Microscopy 126, 123-143.

CARAfoli, E. \& Crompton, M. (1978). The regulation of intracellular calcium by mitochondria. Annals of the New York Academy of Sciences 307, 269-284.

ČerKasov, J., Čerkasovová, A., Kulda, J. \& VilhelMOVA, D. (1978). Respiration of hydrogenosomes of Tritrichomonas foetus. I. ADP dependent oxidation of malate and pyruvate. Journal of Biological Chemistry 253, 1207-1214.

ČerKasovoví, A., ČerKasov, J. \& Kulda, J. (1984). Metabolic differences between metronidazole resistant and susceptible strains of Tritrichomonas foetus. Molecular and Biochemical Parasitology 11, 105-118.

Chapman, A., Cammack, R., Linstead, D. \& Lloyd, D. (1985). The generation of metronidazole radicals in hydrogenosomes isolated from Trichomonas vaginalis. Journal of General Microbiology 131, 2141-2144.
Greenawalt, J. W., Rossi, C. S. \& Lehninger, A. L. (1964). Effect of active accumulation of calcium and phosphate ions on the structure of rat liver mitochondria. Journal of Cell Biology 23, 21-38.

HoNigBERG, B. M. (1978a). Trichomonads of veterinary importance. In Parasitic Protozoa, vol. 2, pp. 163-173. Edited by J, P. Kreier. New York: Academic Press.

HonigberG, B. M. (1978b). Trichomonads of importance in human medicine. In Parasitic Protozoa, vol. 2, pp. 275-454. Edited by J. P. Kreier. New York: Academic Press.

Kitchener, K. R., Meshnick, S. R., Fairfield, A. S. \& WANG, C. C. (1984). An iron-containing superoxide dismutase in Tritrichomonas foetus. Molecular and Biochemical Parsitology 12, 95-99.

LINDMARK, D. G. \& MülleR, M. (1973). Hydrogenosome, a cytoplasmic organelle of the anaerobic flagellate Tritrichomonas foetus and its role in pyruvate metabolism. Journal of Biological Chemistry 248, 7724-7748.

LiNDMARK, D. G. \& MÜLleR, M. (1974). Superoxide dismutase in the anaerobic flagellates, Tritrichomonas foetus and Monocercomonas sp. Journal of Biological Chemistry 249, 4634-4637.

Lloyd, D., LindMaRK, D. G. \& MülleR, M. (1979). Respiration of Tritrichomonas foetus: absence of detectable cytochromes. Journal of Parasitology 65, 466-469.

MarczaK, R., Gorrell, T. E. \& Müller, M. (1983). 
Hydrogenosomal ferredoxin of the anaerobic protozoan, Tritrichomonas foetus. Biological Chemistry 258, 12427-12433.

MüLlER, M. (1980). The hydrogenosome. Symposia of the Society for General Microbiology 30, 127-142.

MülLER, M. \& LINDMARK, D. G. (1978). Respiration of hydrogenosomes of Tritrichomonas foetus. II. Effect of $\mathrm{CoA}$ on pyruvate oxidation. Journal of Biological Chemistry 253, 1215-1218.

MUNK, N. \& RosenberG, H. (1969). On the deposition and utilization of inorganic pyrophosphate in Tetrahymena pyriformis. Biochimica et biophysica acta 177, 629-640.
NiELSEN, M. H. (1976). The fine structure of cells of Trichomonas vaginalis Donne obtained from the exponential phase of growth and from shaking cultures. Acta pathologica et microbiologica scandinavica B84, 205-216.

OHNISHI, T., Lloyd, D., LindMARK, D. G. \& MülleR, M. (1980). Respiration of Tritrichomonas foetus: components detected in hydrogenosomes and in intact cells by electron paramagnetic resonance spectrometry. Molecular and Biochemical Parasitology 2, 39-50. 